Research Article

Lixia Wang, Xingpin Chen*, Tianhong Luo*, Haitao Ni, Lin Mei, Ping Ren, Qing Liu, Yongfeng Ding, and Lijun Zhao

\title{
Effect of cross cold rolling and annealing on microstructure and texture in pure nickel
}

https://doi.org/10.1515/rams-2020-0016

Received Sep 15, 2019; accepted Mar 02, 2020

Abstract: The microstructure and texture in pure nickel were investigated during multi-step cross cold rolling (CCR) and subsequent annealing. It was found that the deformation texture in the CCR nickel was dominated by Brass and rotated Brass about normal direction (ND) $\left(\mathrm{Bs}^{N D}\right)$ texture components, along with marginal cube textures. The resulted deformation textures had a significant effect on the recrystallization behavior. Annealing of the CCR nickel at $550^{\circ} \mathrm{C}$ for $1 \mathrm{~h}$ led to the formation of dominant <012> // ND fiber accompanied by minor rotated cube textures, rather than strong cube texture. Increasing the annealing temperature up to $800^{\circ} \mathrm{C}$ resulted in further enhancement of $<012>/ /$ ND fiber textures. The possible reasons for recrystallization behavior in annealed CCR sample were discussed based on in-situ annealing experiments from two aspects of oriented nucleation and oriented growth theories.

Keywords: Pure nickel; Cross cold rolling; Cube orientation; Recrystallization textures

\footnotetext{
*Corresponding Author: Xingpin Chen: College of Materials Science and Engineering, Chongqing University, Chongqing, 400044, China; Email: xpchen@cqu.edu.cn; Tel.: +86 23 65111547; Fax: +862365106407

Lixia Wang: School of Intelligent Manufacturing Engineering, Chongqing University of Arts and Science, Chongqing, 402106, China; College of Materials Science and Engineering, Chongqing University, Chongqing, 400044, China

*Corresponding Author: Tianhong Luo, Yongfeng Ding, Lijun Zhao: School of Intelligent Manufacturing Engineering, Chongqing University of Arts and Science, Chongqing, 402106, China Haitao Ni: College of Chemistry and Environmental Engineering, Chongqing University of Arts and Science, Chongqing, 402106, China

Lin Mei, Ping Ren, Qing Liu: College of Materials Science and Engineering, Chongqing University, Chongqing, 400044, China
}

\section{Introduction}

The recrystallization textures have been researched by metallurgists for several decades. It is usually found that the cube texture $(\{001\}<100>)$ is the main recrystallization texture component after annealing for most deformed facecentered cubic (FCC) metals with medium to high stacking fault energy (SFE). With respect to the origin of cube texture, both theories of oriented nucleation and oriented growth have been proposed for a long time [1, 2]. However, it remains controversial which one is the dominant mechanism for the generation of sharp cube texture. According to oriented nucleation theory, the nucleation of cube-oriented grains prefers to occur in the pre-existing cube-oriented regions in the deformed metals [3]. Generally, the cube orientation regions, which lie in the long and thin deformation bands, are characterized by a large orientation gradient and lower stored energy. Such features lead to a higher nucleation rate for cube-oriented grains than other orientation grains, and thus the cube bands become very potent nucleation sites during recrystallization annealing $[4,5]$. In contrast, the oriented growth theory asserts that the strong cube texture is attributed to the selective growth of cube nuclei. In other words, the cubeoriented grains grow faster than other grains due to its special relationship with the surrounding deformed matrix [1]. It has been demonstrated that the boundaries with a misorientation angle of $40 \sim 60^{\circ}$ around $<111>$ axis have a higher migration rate during recrystallization [6]. That is to say, the oriented growth mechanism emphasizes the importance of the misorientation environments around the cube-oriented regions for the formation of sharp cube texture.

The formation of the recrystallization cube texture in metal materials with medium to high SFE can be affected by processing parameters, such as change of strain path, strain reduction and annealing temperatures [7]. Among these factors, the change of strain path during rolling (i.e. rotating the sample by $90^{\circ}$ around the normal direction (ND) after each rolling pass, named by "cross cold rolling”) can dramatically alter the deformation texture 
and microstructure, and consequently influence the recrystallization behavior [8-12]. It has been found that the recrystallization texture in cross-rolled FCC samples with medium and high SFE is commonly weakened or randomized [9-13], in comparison with the strong recrystallization cube texture in the straight-rolled and annealed counterpart. The investigation by Bhattacharjee et al. [10] not only demonstrated the disappearance of preferential nucleation of cube grains during recrystallization in the cross-rolled pure nickel, but also attributed the annealing twining to the resulted recrystallization texture. The formation of weaken cube texture was also reported in various copper and copper alloys subjected to cross-rolling and annealing as well as the friction stir welding and the subsequent cooling [11-15]. In addition, the development of unusual recrystallization textures was reported in duplex alloys and high entropy alloys, and the results evidenced the different mechanism were contributed to the recrystallized textures [16-18]. In the present work, there are two concerns to be paid attention in the cross-rolled and annealed pure nickel, which are important for enriching the mechanism of recrystallization. On one hand, the reasons for the disappearance of strong cube texture; on the other hand, the evolution of recrystallization textures was tracked and discussed by ex-situ and in-situ annealing experiments during annealing of cross-rolled pure nickel.

\section{Experimental}

The commercial pure nickel (purity 99.95\%) was used as the starting material. Sheets with dimension $15 \mathrm{~mm} \times 10$ $\mathrm{mm} \times 5.3 \mathrm{~mm}$ were machined from the slabs and subjected to multi-step cross cold rolling (CCR) by a laboratory mill with a roll diameter of $80 \mathrm{~mm}$. The schematic diagram of CCR is depicted in Figure 1. An equivalent true strain of $\epsilon$ $=0.09$ per pass was imparted to the samples. The total deformation reduction in thickness was up to $90 \%$, and the corresponding equivalent strain was 2.66 .

Annealing treatments were carried out on the CCR samples to study the recrystallization behavior. Firstly, the deformed samples were isothermally annealed for $1 \mathrm{~h}$ at different temperatures in a tube furnace with protective atmosphere, and then hardness measurement was employed on these samples to identify the temperature for full recrystallization. Secondly, the CCR sample was annealed at $550^{\circ} \mathrm{C}$ with accumulated annealing times of 10, 25, 45 and $90 \mathrm{~min}$. In detail, after the first $10 \mathrm{~min}$ annealing, the longitudinal section of the sample as defined by RD and ND was ground and then electrolytically polished. Sequentially, some micro-hardness marks were made on the polished surface in order to identify the mapped areas after each annealing step. In order to protect the polished surface, the sample was enclosed in a vacuum glass tube with $\mathrm{Ar}$ atmosphere during the subsequent annealing treatments. The microstructure was characterized at the same region on the samples after each annealing step.

In the present study, the microstructure on the longitudinal section was examined by electron backscatter diffraction (EBSD) system attached to TESCAN MIRA 3 field emission gun-scanning electron microscope. A step size of $0.2 \mu \mathrm{m}$ was used for each condition with RD as the horizontal direction during in situ annealing. Due to the limited angular resolution of the EBSD technique, a critical misorientation angle of $2^{\circ}$ was defined to identify boundaries in the orientation maps, where low angle grain boundaries (LAGBs) and high angle grain boundaries (HAGBs) were identified by misorientations of $2-15^{\circ}$ and $>15^{\circ}$, respectively. Annealing twin boundaries were defined by a misorientation of $60^{\circ}$ with a tolerance of $8.66^{\circ}$, according to Brandon's criterion $\Delta \theta_{\max }=15^{\circ} \Sigma^{-1 / 2}$ [19], regardless of their coherent versus incoherent character. The average grain size was calculated without considering twin boundaries.

Macro-textures of the samples in different conditions were measured by X-ray diffraction (XRD, Rigaku D/max2500 PC). From three incomplete pole figures $\{100\},\{110\}$ and $\{111\}$, the three-dimensional orientation distribution functions (ODFs) were calculated, and the orientations were expressed in terms of the Euler angles $\left(\varphi_{1}, \Phi, \varphi_{2}\right)$. It should be noticed that for unidirectional rolling (UDR) deformation the orthorhombic sample symmetry can be assumed. However, due to the strain path change between two consecutive passes, CCR was associated with the monoclinic sample symmetry [20, 21]. Consequently, $\varphi_{1}$ ranging from $0^{\circ}$ to $180^{\circ}$ was adopted in the case of CCR samples. The volume fractions of different texture components were determined within a spread of $15^{\circ}$ around their respective ideal locations in Euler space by Labotex, where $\{001\}<100>$ (Cube), $\{072\}<027>$ (TD-rotated Cube orientation, named by Cube $^{T D}$ ), $\{012\}<100>$ (RD-rotated Cube orientation, named by Cube ${ }^{R D}$ ), $\{122\}<212>$ (Cube-Twin), $\{110\}<112>$ (Brass), $\{110\}<223>$ (ND-rotated Brass orientation, named by Brass ${ }^{N D}$ ), $\{123\}<634>(\mathrm{S}),\{112\}<111>$ (Copper), and $\{011\}<100>$ (Goss) were considered.

To evaluate the recrystallization process, the Vickers hardness measurements were performed on each sample using a load of $300 \mathrm{~g}$ with a dwell time of $15 \mathrm{~s}$. In order to ensure the statistical analysis, at least 10 indentations were made for each specimen to obtain an average value. 


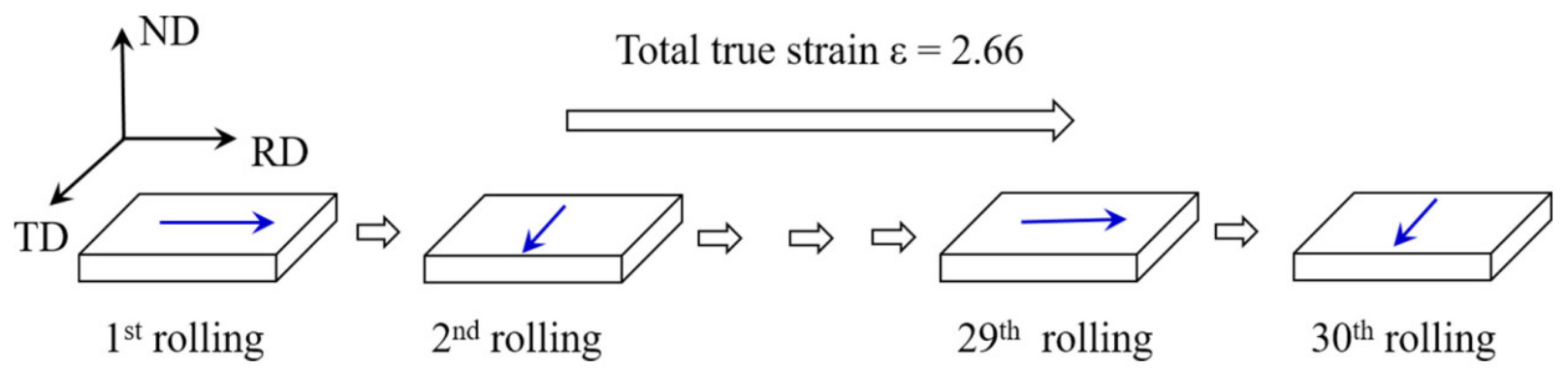

Figure 1: Schematic diagram of the multi-step cross cold rolling employed in the present study.

\section{Results and discussion}

\subsection{Deformation microstructure and texture in CCR nickel}

The microstructure and macro-texture of as-received pure nickel (99.95\%) can be seen from orientation image map (Figure 2a) and grain boundary map (Figure 2b) as well as pole figures (PFs) (Figure 2c). The microstructure composes of the equiaxed grains with the average grain size of $25 \mu \mathrm{m}$ and profuse annealing twin boundaries with red lines. The start texture of the as-received materials can be depicted as the relatively weak $<100>/ /$ ND fiber.

The EBSD orientation image map (OIM) on the TD plane for deformed sample is displayed in Figure 3a, which depicts the microstructure character and identifies orientations of grains with different colors. In this map, LAGBs and HAGBs are represented by black and grey lines, respectively. It can be observed that the deformation microstructure is dominated by the lamellar microstructure accompanied by minor intersecting deformation bands. From the view of micro-texture, the orientations for lamellar deformation bands could be described mainly in the terms of superposition of $\mathrm{Bs}$ and $\mathrm{Bs}^{N D}$, together with minor cube and rotated-cube orientations. The results are broadly in line with reports by Bhattacharjee [10, 19], which demonstrate that a finer grain sized material shows stronger rotatedbrass than a coarse grain size material subjected to crossrolling [19]. The reasons for the observation of few Copper and $\mathrm{S}$ orientations has been interpreted from the view of the orientations unstability when the rolling direction is changed during cross-cold rolling $[8,11,12]$. Moreover, it should be to note that the cube-oriented deformation bands are found to be adjacent to RD and/or TD rotated cube bands along RD. It is known that Bhattacharjee [5] previously reported that the RD-rotated cube bands developed at the expense of cube-oriented bands during unidirectional rolling of nickel. Thus, it can be speculated that the observation of RD- and TD-rotated cube-oriented bands is probably attributable to the alternative rolling direction between $R D$ and TD after each pass during the CCR deformation mode. However, the presence of rotated cube orientations that are neighbor to cube orientation apparently destroyed the continuity of cube-oriented bands as shown in Figure 3a. As a result, the misorientation gradient in the cube-oriented bands could be influenced. In the current work, the accumulated misorientation as well as the point-to-point misorientation distribution along the blue arrows (Figure 3a) in deformed cube-oriented bands is displayed in Figure 3b. The point-to-point misorientation values varies in a small range below 4 degrees, but the accumulated misorientation showed a relatively higher misorientation accumulation. Nevertheless, this misorientation gradient is not enough high as that in the UDR counterpart [22]. Thus, it can be obtained that the cross cold rolling mode not only makes the cube orientation rotate toward RD and TD, but also has an influence on the misorientation gradient in the cube-oriented bands.

A complete depiction of macro-texture of the CCR deformed samples is done by presenting $\varphi_{2}$ constant sections of ODFs as shown in Figure 4. The important deformation and recrystallization texture components in the CCR samples are summarized in Table 1 . In $\varphi_{2}=0^{\circ}$ section, it could be obviously observed that the maximum intensity of texture was located at $\left(\varphi_{1}, \Phi, \varphi_{2}\right)=\left(42^{\circ}, 45^{\circ}, 0^{\circ}\right)$ which can be referred to as $\mathrm{Bs}^{N D}$ due to its deviation from the ideal Brass along ND. The results are consistent with the previous reports that a finer grain sized material subjected to cross-rolling shows strong rotated-brass [23]. Besides the dominant $\mathrm{Bs}^{N D}$ orientation, a small amount of Cube ${ }^{R D}$ locating at $\left(0^{\circ}, 20^{\circ}, 0^{\circ}\right)(\{013\}<100>)$ and Cube ${ }^{T D}$ locating at $\left(90^{\circ}, 16^{\circ}, 0^{\circ}\right)(\{072\}<027>)$ is also found, not only cube orientation as reported previously [12]. This observation can be corroborated from the EBSD orientation image map in Figure 3a. From $\varphi_{2}=45^{\circ}$ and $65^{\circ}$ sections, it could be verified that Copper and $\mathrm{S}$ were nearly absent in the cross- 

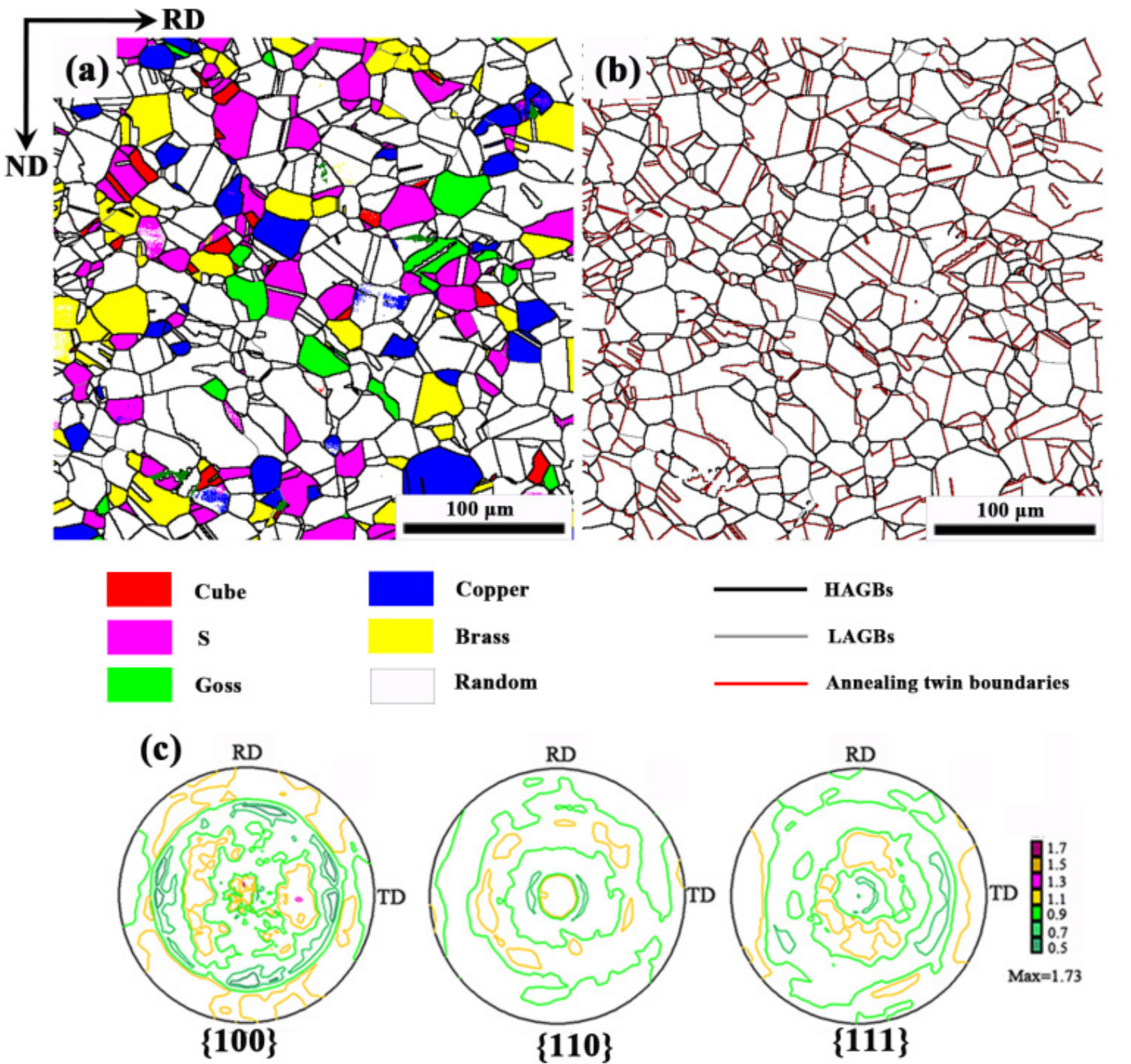

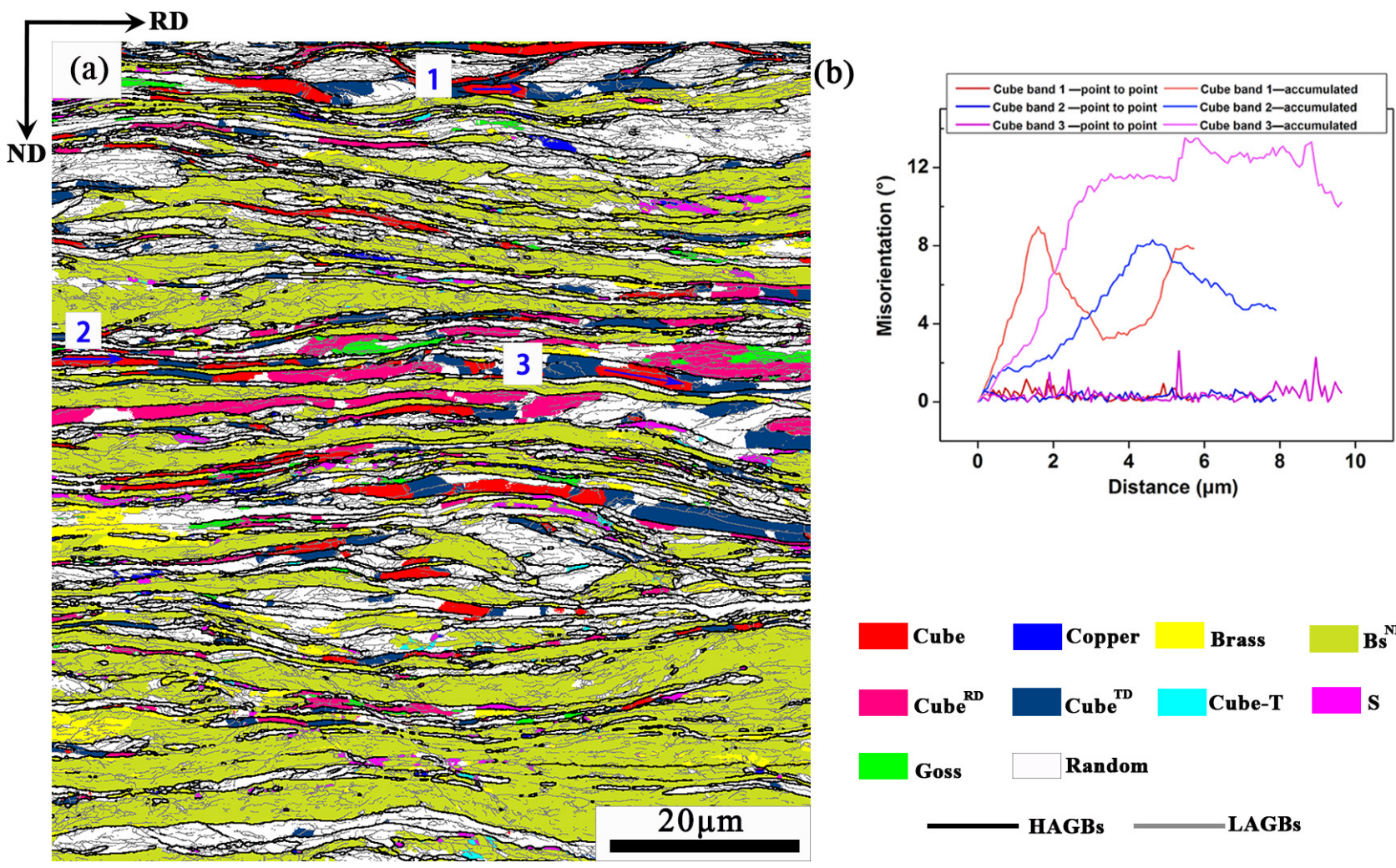

Figure 3: (a) EBSD orientation map displaying deformation microstructure for deformed nickel and (b) the point-to-point and accumulated misorientation in cube-oriented deformation bands.

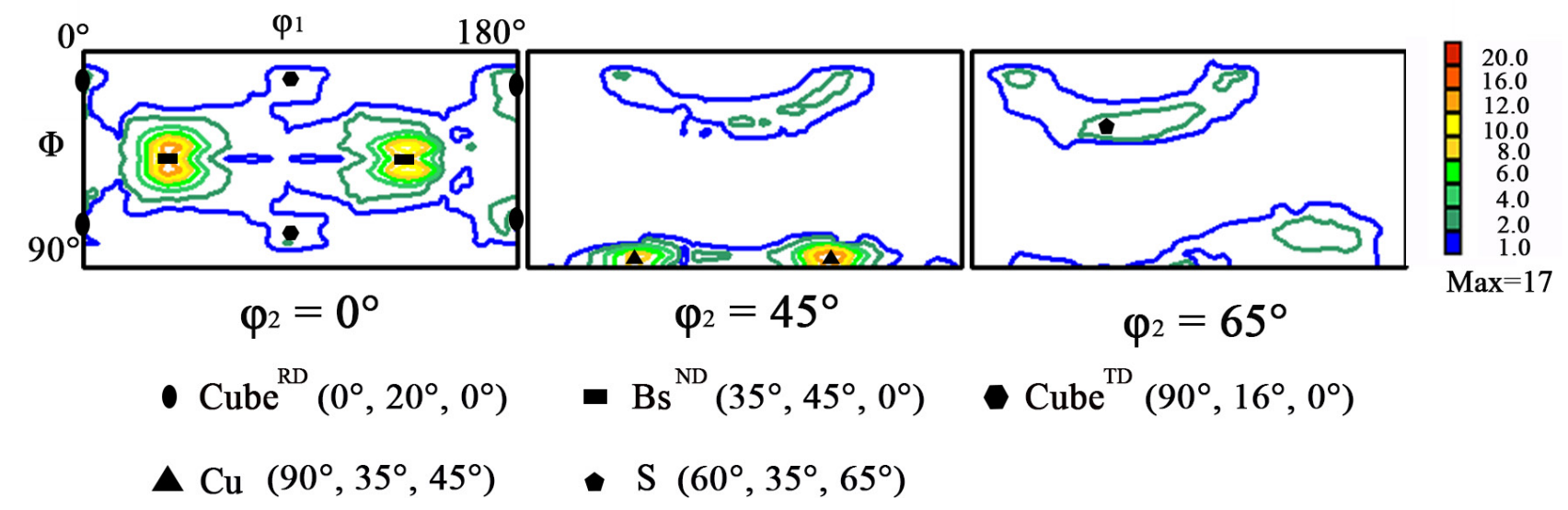

Figure 4: $\varphi_{2}=0^{\circ}, 45^{\circ}, 65^{\circ}$ sections for the cross cold rolling samples.

ary misorientation distribution in Figure 6b evidences the high length fraction of annealing twin boundaries of $40.7 \%$ but low fraction of LAGBs of $2.8 \%$, both of which indicate the weakened preferred orientation in the microstructure [24].

To elucidate the recrystallization textures in detail, the ODF in the presence of $\varphi_{2}=0^{\circ}$ section is displayed in Figure 6c. The main recrystallization textures in the low-temperature annealed CCR samples could be approx- imated as <012>//ND fibers in black dotted line and $<021>/ /$ ND fibers in biue dotted line, including rotated Cube texture component Cube $^{R D}\{013\}<100>$ and the newly formed texture components marked with different symbols as shown in Table 1 . These two fibers can be referred to as $<012>/ / N D$ fibers. It is noticed that although obvious cube-oriented deformed regions are observed in the deformed microstructure (Figure 3a), the cube texture does not develop in the recrystallized CCR samples. 
Table 1: Important deformation and recrystallization texture components in CCR samples.

\begin{tabular}{|c|c|c|c|}
\hline Texture components & Symbol & $\begin{array}{c}\text { Euler angle }\left(^{\circ}\right) \\
\left(\varphi_{1}, \Phi, \varphi_{2}\right)\end{array}$ & Miller indices \\
\hline $\mathrm{Bs} / \mathrm{Bs}^{N D}$ & & $(35-45,45,0)$ & $\{011\}<u v w>$ \\
\hline Cube $\mathrm{e}^{R D}$ & 0 & $(0,20,0)$ & $\{013\}<100\rangle$ \\
\hline Cube $^{T D}$ & & $(90,16,0)$ & $\{027\}<072>$ \\
\hline$S$ & & $(60,35,65)$ & $\{123\}<634>$ \\
\hline \multirow[t]{7}{*}{$\mathrm{Cu}$} & & $(90,35,45)$ & $\{112\}<111>$ \\
\hline & & $(24,30-33,0)$ & $\{012\}<421>$ \\
\hline & $\square$ & $(62-66,30,0)$ & $\{012\}<121>$ \\
\hline & 0 & $(82,27,0)$ & $\{012\}<163\rangle$ \\
\hline & & $(24,60-64,0)$ & $\{021\}<412\rangle$ \\
\hline & & $(62-66,60,0)$ & $\{021\}<112>$ \\
\hline & 0 & $(82,63,0)$ & $\{021\}<136\rangle$ \\
\hline
\end{tabular}

Table 2: Volume fractions (\%) of the texture components in different conditions

\begin{tabular}{cccccccc}
\hline & $\mathrm{S}$ & $\mathrm{Cu}$ & $\mathrm{Bs}$ & Bs $^{N D}$ & Cube & Cube $^{T D}$ & $\mathrm{Cube}^{R D}$ \\
\hline $\mathrm{CCR}$ & 4.4 & 0.5 & 38.4 & 41.3 & 2.5 & 6.9 & 4.4 \\
Annealing at $550^{\circ} \mathrm{C}$ & 6.3 & 4.1 & 8.0 & 8.9 & 3.0 & 6.4 & 3.7 \\
Annealing at $800^{\circ} \mathrm{C}$ & 3 & 0.8 & 12.7 & 13.3 & 1.4 & 2.9 & 1.2 \\
\hline
\end{tabular}

Figure 7 shows the microstructure and texture of the cross-rolled samples subjected to high-temperature annealing at $800^{\circ} \mathrm{C}$. In comparison with low-temperature annealing, the grains are uniformly coarsened with average size of $41.7 \mu \mathrm{m}$, indicating of the normal grain growth during high-temperature annealing. The annealing twin boundaries are widely distributed in the microstructure (Figure 7a), which correspond well with the relatively high fraction of $43.1 \%$ calculated from the grain boundary misorientation distribution (Figure $7 \mathrm{~b}$ ). Furthermore, it can be found that the annealing temperatures play a minor role on the character of grain boundary misorientation distribution (Figure $6 \mathrm{~b}$ and Figure $7 \mathrm{~b}$ ), except of a slight increase of annealing twin boundaries and LAGBs at higher temperature, which clear indicate that a similar and weak textures develop in the low- and high-temperature annealed samples [24]. The detailed textures are represented by ODF of $\varphi_{2}=0^{\circ}$ section. The $\varphi_{2}=0^{\circ}$ section shows the development of $<012>/ /$ ND fibers in black dotted line and $<021>/ /$ ND fibers in blue dotted line. The intensities of recrystallized textures get enhanced in comparison with that in the $550^{\circ} \mathrm{C}$ annealed samples. Meanwhile neither of Cube ${ }^{R D}$ and Cube $^{T D}$ texture components are observed in the high-temperature annealed samples as compared with the low-temperature annealed samples. Therefore, it is necessary to investigate the evolution of recrystallization textures during recrystallization in the annealed CCR samples. 


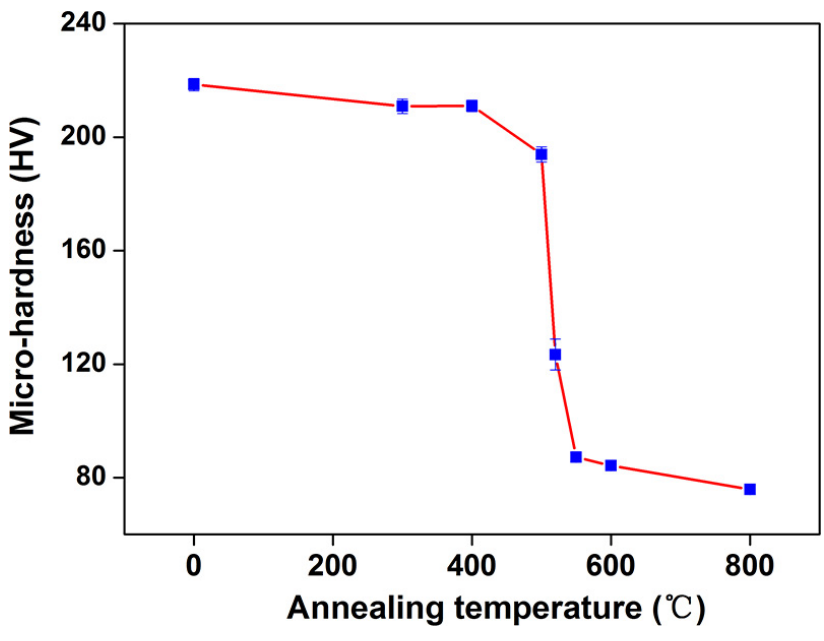

Figure 5: Micro-hardness evolution for CCR samples subjected to annealing at $0-800^{\circ} \mathrm{C}$ for $1 \mathrm{~h}$.

\subsection{Microstructure evolution during in-situ annealing in the CCR nickel}

In order to investigate the mechanism of the disappearance of cube orientation as well as mechanism of recrystallization texture in the cross-rolled and annealed samples, in-situ annealing experiments at $550^{\circ} \mathrm{C}$ were carried on the CCR samples.

Figure 8 shows the gradual evolution of microstructure at the same region characterized by EBSD technique during in-situ annealing with annealing steps of $10 \mathrm{~min}$, $20 \mathrm{~min}, 45 \mathrm{~min}$ and $90 \mathrm{~min}$. In the following, we will define the recrystallizing nuclei/grain as just grains. Figure $8 \mathrm{a}$ shows the microstructure at the initial stage of recrystallization, the microstructure is dominated by lamellar deformation bands and meanwhile a few strained-free grains surrounded by deformation bands could be clearly observed after annealing for $10 \mathrm{~min}$. It's more important to note that early nucleation and growth of cube-oriented grains are obviously observed, but cube grains are not totally separated by HAGBs compared with non-cube grains. With accumulated annealing time extending to $30 \mathrm{~min}$, the deformed matrix was rapidly swept out by the newly formed grains as well as the growing recrystallized grains, as shown in Figure 8b, which resulted in a partial recrystallized microstructure. More importantly, the large recrystallized grains are found to have non-cube orientation. Interestingly, cube-oriented regions as well as $\mathrm{Bs} / \mathrm{Bs}^{N D}$ orientation bands are still in deformed state. After additional annealing for $45 \mathrm{~min}$, the microstructure was dominated by the recrystallized grains, together with minor $\mathrm{Bs} / \mathrm{Bs}^{N D}$. oriented deformation matrix (Figure 8c). Moreover, the non-cube oriented grains have grain size advantage in comparison with cube grains. Extending annealing time (Figure 8d) does not make a distinct difference on the microstructure due to the reduced stored energy.

One important issue would be clarified why sufficient cube-oriented deformation bands do not develop a strong cube texture in the CCR sample? The significant thin cube deformation bands accompanied by the neighbored rotated-cube orientation are clearly observed at the initial stage of recrystallization as shown in Figure 8a. The cube-oriented deformation bands have been reported as the important preferential nucleation site due to its unique structure in the UDR processes materials [22]. In the present case the cube-oriented deformation bands are characterized by recovery structure with a few LAGBs in the cube-oriented bands and misorientation gradient (Figure $3 \mathrm{~b}$ ) compared with other deformation bands, which indicates that the cube bands are the possible nucleation site. In fact, bulge formation into neighboring deformed matrix is observed for the cube bands marked with blue arrow in Figure 8a. In addition, it was also found that most of cube-oriented bands are surrounded with Bs/Bsoriented regions, indicating cube-oriented regions have a large misorientation with deformed matrix. However, with increasing annealing time the recrystallized cube-oriented grains do not have a size advantage in comparison with the noncube-oriented grains nucleated at the initial stage. Previously, several literatures $[6,25,26]$ demonstrated that the size advantage of cube-oriented grains was attributed to the higher growth rate for the cube-oriented grains misoriented $40 \sim 60^{\circ}$ with surrounded matrix about $<111>$ axis in the unidirectionally rolled specimens. Lin et al. [26] demonstrated that the higher growth rate for super-cube oriented grains was related to the preferential growth into S-oriented matrix. In the present work, the deformation textures of the CCR sample were characterized by Bs and Bs-ND components. The misorientation relationship between cube-oriented regions and their main surrounding matrix (Bs ${ }^{N D}$ component) can be characterized by the axisangle misorientation relationship of $56^{\circ}<1-32>$. Thus, it can be speculated that the adverse misorientation environment around the cube-oriented regions in the CCR sample ultimately suppressed the growth of the cube-oriented grains, leading to no observation of strong cube texture.

\subsection{Texture evolution during in-situ annealing in the CCR nickel}

The micro-texture evolution during in-situ annealing is displayed in Figure 9. The $\varphi_{2}=0^{\circ}$ sections of ODF are shown to highlight the texture changes during annealing. 

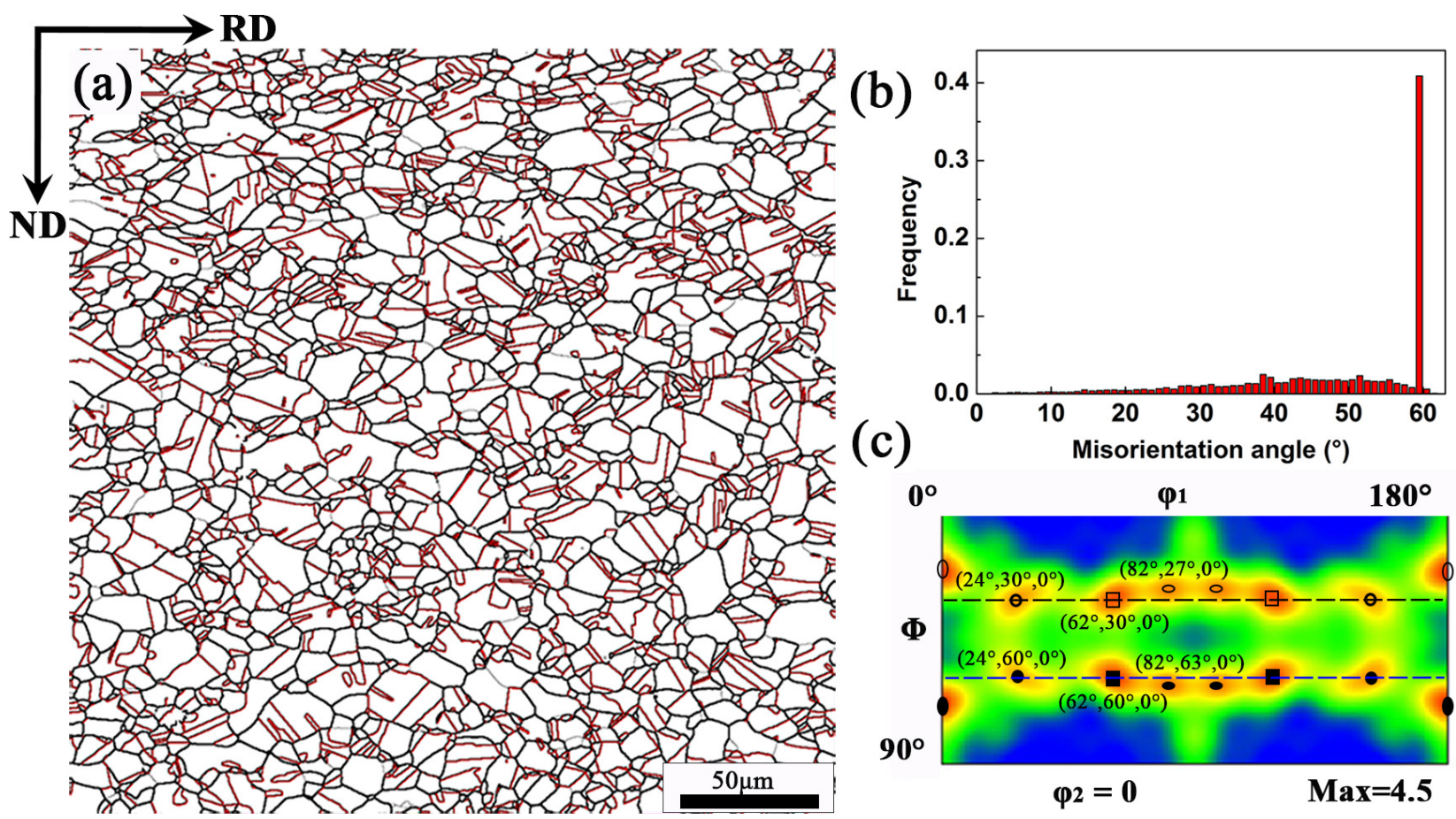

Figure 6: (a) Grain boundary map showing microstructure, (b) misorientation distribution map and (c) $\varphi_{2}=0^{\circ}$ section ODF of the sample annealed at low temperature of $550^{\circ} \mathrm{C}$ for $1 \mathrm{~h}$.

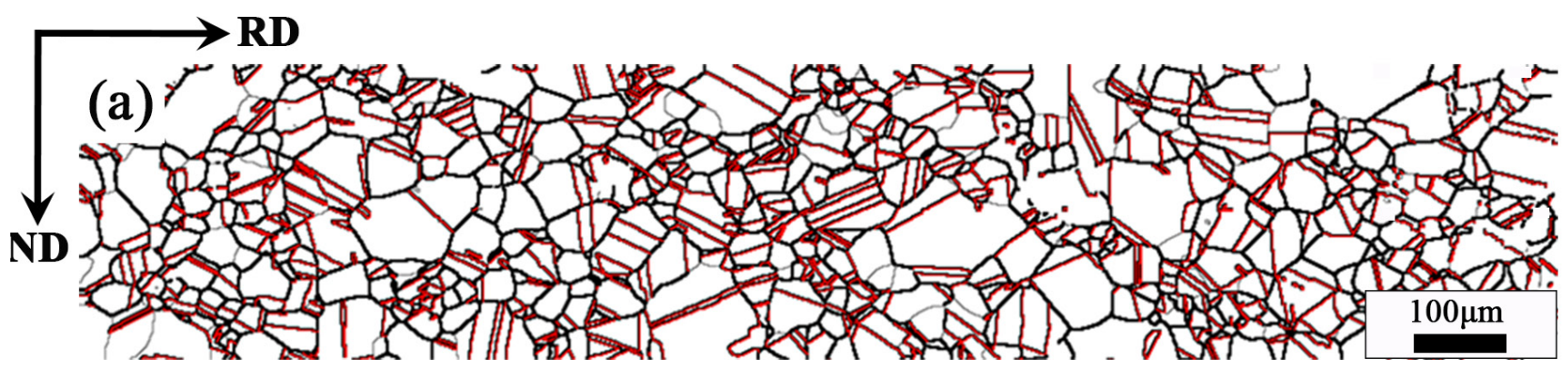

(b)

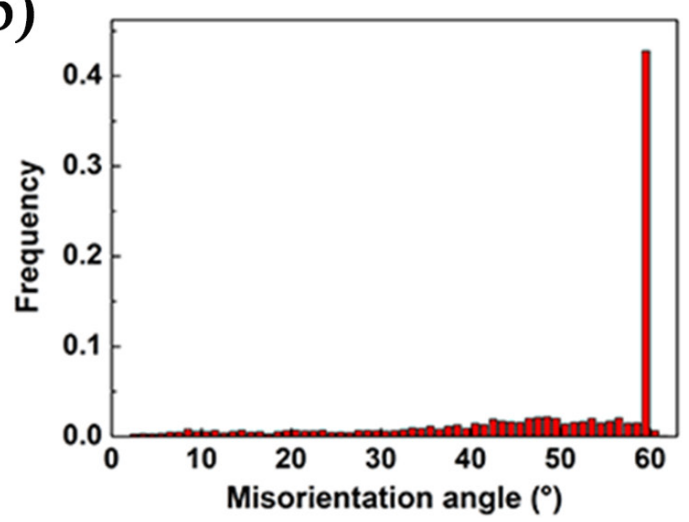

(c)

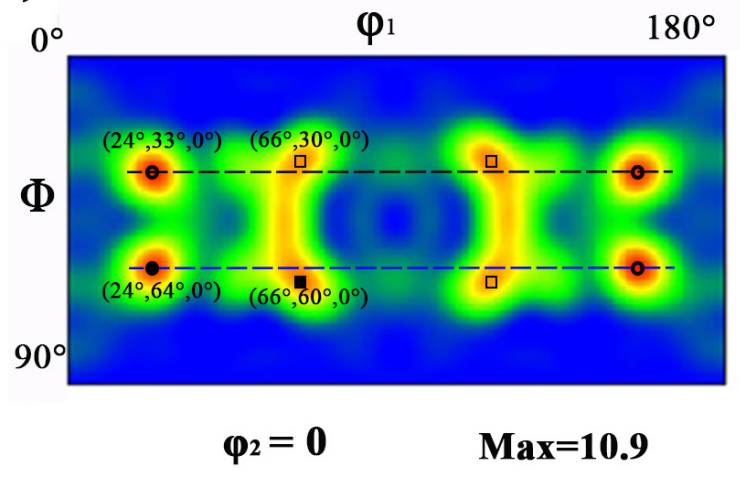

Figure 7: (a) Grain boundary map showing microstructure, (b) misorientation distribution map and (c) $\varphi_{2}=0^{\circ}$ section ODF of the sample annealed at high temperature of $800^{\circ} \mathrm{C}$ for $20 \mathrm{~min}$. 

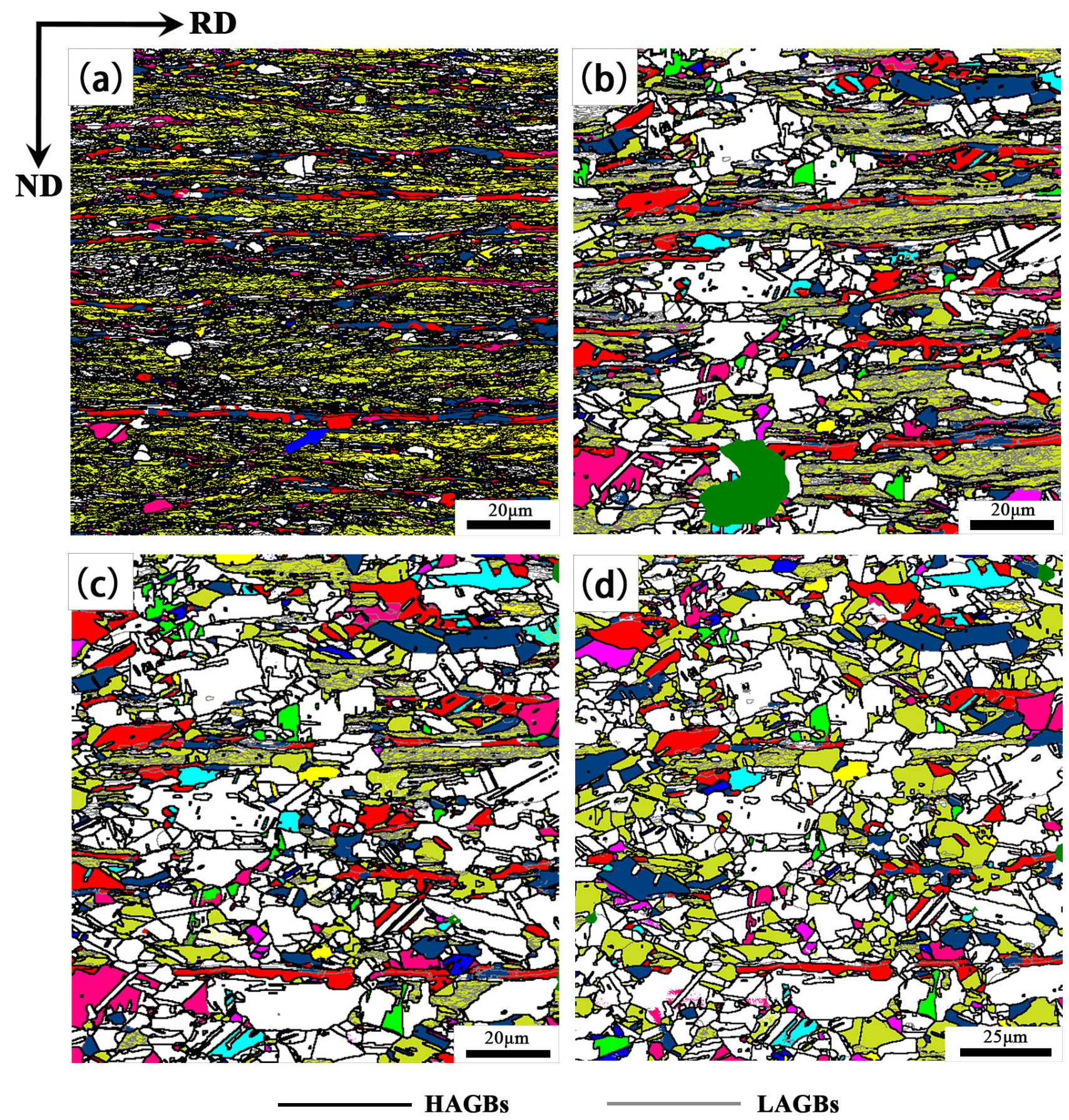

Figure 8: Microstructure evolution of the CCR processed nickel during in-situ annealing at $550^{\circ} \mathrm{C}$ for (a) $10 \mathrm{~min}$, (b) $20 \mathrm{~min}$, (c) $45 \mathrm{~min}$ and (d) $90 \mathrm{~min}$.

As can be seen that when the CCR samples were slightly annealed for $10 \mathrm{~min}$ (Figure 9a), the $\varphi_{2}=0^{\circ}$ section shows intensity at the vicinity of $\mathrm{Bs}^{N D}(\{011\}<322>)$, which is confirmed from the orientation map shown in Figure 8a. As the prolongation of annealing time, the major texture component $B s^{N D}$ gradually shifted along ND toward Bs orientation $(\{011\}<211>)$, accompanied by the significant decrease of peak intensity from 30.1 to 5.2. Meanwhile, the newly formed texture component $\{012\}<121>$ belonging to the $<012>$ // ND fibers gets enhanced as shown in Figure 9c and Figure $9 \mathrm{~d}$, which is also observed in the ex-situ annealed samples as shown in Figure 6c and Figure 7c. It is worth to note that the recrystallized non-cube grains gradually swept out cube bands, but the formation of cube-oriented grains is also observed, therefore the volume fraction of cube texture has no distinct variation (Table 3). It must be 


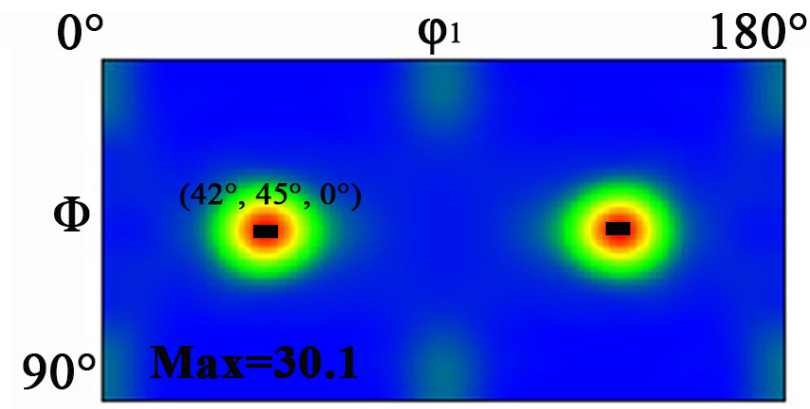

(a)

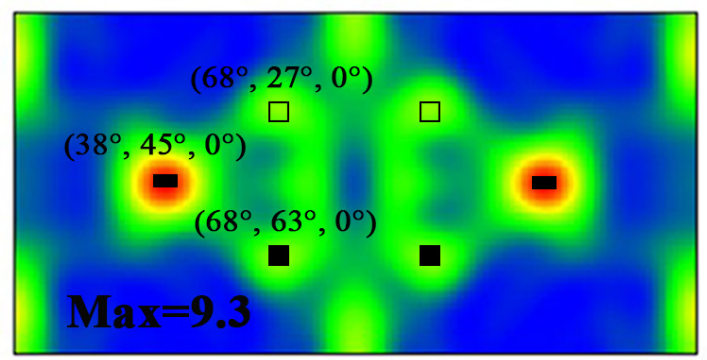

(c)

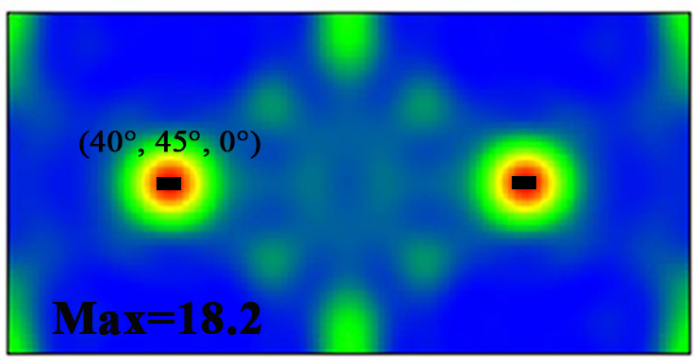

(b)

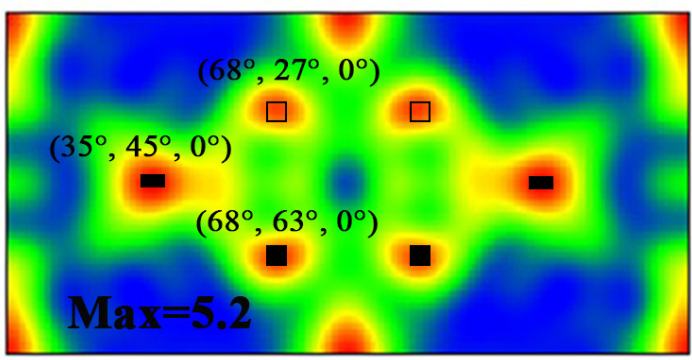

(d)

Figure 9: Micro-texture evolution of the CCR processed nickel during in-situ annealing at $550^{\circ} \mathrm{C}$ for (a) $10 \mathrm{~min}$, (b) $20 \mathrm{~min}$, (c) $45 \mathrm{~min}$ and (d) $90 \mathrm{~min}$.

Table 3: Volume fraction (\%) of texture components during in-situ annealing at $550^{\circ} \mathrm{C}$

\begin{tabular}{lccccccc}
\hline & Cube & Cube $^{R D}$ & Cube $^{T D}$ & Bs & Bs $^{N D}$ & $(68,27,0)$ & $(68,63,0)$ \\
\hline $10 \mathrm{~min}$ & 7.4 & 4.4 & 10 & 38.3 & 46.7 & 4.8 & 4.1 \\
$20 \mathrm{~min}$ & 8.3 & 3.8 & 11.5 & 24.3 & 28.5 & 12.8 & 5.7 \\
$45 \mathrm{~min}$ & 8.5 & 4.7 & 11 & 14.8 & 17.7 & 15.7 & 7.7 \\
$90 \mathrm{~min}$ & 7.1 & 3.6 & 11 & 11.3 & 14 & 17 & 8.5 \\
\hline
\end{tabular}

mentioned that the misorientation relationship between $\mathrm{Bs} / \mathrm{Bs}^{N D}$ and cube grains is not favorable for the preferential growth of cube grains in the CCR samples, therefore the growth of cube grains would be suppressed. One point should be stated that the microtexture difference between in-situ (Figure 9) and ex-situ (Figure 6c and Figure 7c) annealed samples is attributed to that the $\varphi_{2}=0^{\circ}$ sections obtained by EBSD represents the orientation distribution of the local regions.

Previously, Bhattacharjee et al. [10] reported the evolution of microstructure and texture in the cross-rolled and annealed nickel, where the deformation texture corresponded well with the results in the present work but the formation of $\mathrm{ND} / /<111>$ recrystallization fiber texture was inconsistent. The formation of $\mathrm{ND} / /<111>$ fiber was attributed to the twin formation of TD-rotated cube component. Furthermore, the $<111>/ /$ ND fibers got weakened at high temperature. In the present case, the $<012>/ / \mathrm{ND}$ fibers are observed regardless of annealing temperature, and the texture intensity gets enhanced in the hightemperature annealed sample. Although the massive annealing twin boundaries are observed, but it can't interpret the mechanism of the formation of $<012>/ /$ ND fibers. Generally, the recrystallization textures are affected by the start microstructure and texture as well as the purity which are probably associated with the discrepancy in recrystallization behavior. It is found that the misorientation relationship between major deformation textures and recrystallization textures which have been calculated as shown in Table 4. It can be seen that the misorientation angles spread between $32-38^{\circ}$, but the rotation axes parallel to $<322>$ which are close to $<111>$ axis. It has been demonstrated that boundaries with high misorientation angle and rotation axes around $<111>$ are favorable for rapid migration [27]. In the present work, the rotation axis $<322>$ is in close proximity to $<111>$ axis, and it can be speculated 
Table 4: Misorientation relationship (angle/axis) between deformation texture and main recrystallization textures

\begin{tabular}{ccc}
\hline Deformation texture & Main recrystallization textures & Misorientation \\
\hline $\operatorname{Bs}^{N D}\left(42^{\circ}, 45^{\circ}, 0^{\circ}\right)$ & $\left(68^{\circ}, 26^{\circ}, 0^{\circ}\right)$ & $32.1^{\circ}<32-2>$ \\
$\operatorname{Bs}\left(35^{\circ}, 45,{ }^{\circ} 0^{\circ}\right)$ & $\left(68^{\circ}, 26^{\circ}, 0^{\circ}\right)$ & $37.9^{\circ}<32-2>$ \\
$\operatorname{Bs}^{N D}\left(42^{\circ}, 45^{\circ}, 0^{\circ}\right)$ & $\left(68^{\circ}, 64^{\circ}, 0^{\circ}\right)$ & $32.1^{\circ}<22-3>$ \\
$\operatorname{Bs}\left(35^{\circ}, 45^{\circ}, 0^{\circ}\right)$ & $\left(68^{\circ}, 64^{\circ}, 0^{\circ}\right)$ & $37.9^{\circ}<22-3>$ \\
\hline
\end{tabular}

that the mobility of boundaries with high misorientation angle and <322> common axis was probably higher than that of other random high angle grain boundaries. Therefore, the enhancement of new recrystallization textures seems to be more affected by the oriented growth theory.

\section{Conclusion}

In the present work, the evolution of microstructure and texture during recrystallization of CCR samples was investigated by using of ex-situ and in-situ EBSD observations. The results of the investigation concern the absence of strong cube texture during recrystallization as well as the recrystallization mechanism in the cross-rolled pure nickel. The following conclusions are obtained.

(1) The deformation textures in the CCR deformed samples are dominated by Brass and ND rotated Brass texture components, along with the minor cube texture and rotated cube textures toward RD and TD.

(2) The absence of strong cube orientation in annealed CCR samples can be interpreted as follows. On one hand, the existence of misorientation gradient in the cube-oriented bands makes the preferential nucleation for cube grains. On the other hand, the surrounding misorientation around the cube bands has an unfavourable effect on the rapid migration of grain boundaries, which led to the loss of growth advantage.

(3) The annealing textures in the CCR and subsequently annealed samples are described as $<012>/ /$ ND fiber, and relatively weak cube texture was observed. The formation of recrystallization textures during cross cold rolling and subsequent annealing seemed to be more affected by the oriented growth theory.

Acknowledgement: This research was funded by the National Natural Science Foundation of China (grant number 51171215, 51421001 and 51601026), National Key R\&D Program of China (grant number 2018YFB2001400), the Science and Technology Research Program of Chongqing $\mathrm{Mu}$ - nicipal Education Commission (grant number KJ1711290) and Local Fund for Chongqing University of Arts and Sciences (grant number R2018SJD19 and WLHX-2019-0549).

\section{References}

[1] Juul Jensen, D. Growth rates and misorientation relationships between growing nuclei/grains and the surrounding deformed matrix during recrystallization. Acta Metallurgica et Materialia, Vol. 43, No. 11, 1995, pp. 4117-4129.

[2] Smallman, R. E., and C. S. Lee. Advances in the theory of deformation and recrystallization texture formation. Materials Science and Engineering A, Vol. 184, No. 2, 1994, pp. 97-112.

[3] Humphreys, F. J. and M. Hatherly. Recrystallization and Related Annealing Phenomena. Elsevier, The Netherlands, 2004.

[4] Zaefferer, S., T. Baudin, and R. Penelle. A study on the formation mechanisms of the cube recrystallization texture in cold rolled Fe-36\%Ni alloys. Acta Materialia, Vol. 49, No. 6, 2001, pp. 11051122.

[5] Bhattacharjee, P. P., Y. Takatsuji, Y. Miyajima, D. Terada, and N. Tsuji. Evolution of Microstructure and Texture During Cold Rolling and Annealing of a highly cube-textured $(\{001\}<100>)$ polycrystalline nickel sheet. Metallurgy and Materials Science, Vol. 43, No. 7, 2012, pp. 2442-2452.

[6] Zhang, Y. B., A. Godfrey, W. Liu, and Q. Liu. Investigation of boundary migration during grain growth in fully recrystallised high purity nickel. Materials Science and Technology, Vol. 26, No. 2, 2010, pp. 197-202.

[7] Suwas, S., and A. K. Singh. Role of strain path change in texture development. Materials Science and Engineering A, Vol. 356, No. 1-2, 2003, pp. 368-371.

[8] Gurao, N. P., S. Sethuraman, and Satyam Suwas. Effect of strain path change on the evolution of texture and microstructure during rolling of copper and nickel. Materials Science and Engineering: $A$, Vol. 528, No 25-26, 2011, pp. 7739-7750.

[9] Pospiech, J., M. Wróbel, J. T. Bonarski, and M. Blicharski. Texture Formation with Different Rolling Modes in Copper. Materials Science Forum, Vol. 408-412, 2002, pp. 613-618.

[10] Bhattacharjee, P. P., M. Joshi, V. P. Chaudhary, J. R. Gatti, and M. Zaid. Texture evolution during cross rolling and annealing of high-purity nickel. Metallurgical and Materials Transactions $A$, Vol. 44, No. 6, 2013, pp. 2707-2716

[11] Öztürk, T. Deformation and recrystallization textures in crossrolled sheets of copper and $\alpha$-brass. Scripta Metallurgica, Vol. 22, No. 10, 1988, pp. 1611-1616.

[12] Hong, S. H., D. N. Lee, and J. Eng. Deformation and recrystallization textures in cross-rolled copper sheet. Journal of Engineering 
Materials and Technology, Vol. 124, No. 1, 2002, pp. 13-22.

[13] Bhattacharjee, P. P., S. Saha, and J. R. Gatti. Effect of Change in Strain Path During Cold Rolling on the Evolution of Microstructure and Texture in $\mathrm{Al}$ and $\mathrm{Al}-2.5 \% \mathrm{Mg}$. Journal of Materials Engineering and Performance, Vol. 23, No. 2, 2014, pp. 458-468.

[14] Ostafin, M., J. Pospiech, and R. A. Schwarzer. Microstructure and texture in copper sheets after reverse and cross rolling. Solid State Phenomena, Vol. 105, 2005, pp. 309-314.

[15] Liu, X. C., Y. F. Sun, T. Nagira, K. Ushioda, and H. Fujii. Evaluation of dynamic development of grain structure during friction stir welding of pure copper using a quasi in situ method. Journal of Materials Science and Technology, Vol. 35, No. 07, 2019, pp. 1412-1421.

[16] Zaid, M. and P. P. Bhattacharjee. Electron backscatter diffraction study of deformation and recrystallization textures of individual phases in a cross-rolled duplex steel. Materials Characterization, Vol. 96, 2014, pp. 263-272.

[17] Reddy, S. R., M. Z. Ahmed, G. D. Sathiaraj, and P. P. Bhattacharjee. Effect of strain path on microstructure and texture formation in cold-rolled and annealed FCC equiatomic CoCrFeMnNi high entropy alloy. Intermetallics, Vol. 87, 2017, pp. 94-103.

[18] Patel, A., I. Wani, S. R. Reddy, S. Narayanaswamy, A. Lozinko, R. Saha, et al. Strain-path controlled microstructure, texture and hardness evolution in cryo-deformed AlCoCrFeNi 2.1, eutectic high entropy alloy. Intermetallics, Vol. 97, 2018, pp. 12-21.

[19] Brandon, D. G. The structure of high-angle grain boundaries. Acta Metallurgica, Vol. 14, No. 11, 1996, pp. 1479-1484.
[20] Suwas, S., and N. P. Gurao. Development of microstructures and textures by cross rolling. Comprehensive Materials Processing, 2014, pp. 81-106.

[21] Rout, M., S. K. Pal, and S. B. Singh. Modern Manufacturing Engineering, Paulo, J., Ed. Davim, Springer Cham, Switzerland, 2015, Chapter 2, pp. 41-64.

[22] Bhattacharjee, P. P., R. K. Ray, and N. Tsuji. Cold rolling and recrystallization textures of a $\mathrm{Ni}-5$ at.\% W alloy. Acta Materialia, Vol. 57, No. 7, 2009, pp. 2166-2179.

[23] Bhattacharjee, P. P., M. Joshi, V. P. Chaudhary, and M. Zaid. The effect of starting grain size on the evolution of microstructure and texture in nickel during processing by cross-rolling. Materials Characterization, Vol. 76, No. 2, 2013, pp. 21-27.

[24] Mishin, O. V., and G. Gottstein. Grain boundary ensembles due to grain growth in copper with strong recrystallization texture. Materials Science and Engineering A, Vol. 249, No. 1-2, 1998, pp. 71-78.

[25] Li, X. L., W. Liu, A. Godfrey, D. Juul Jensen, and Q. Liu. Development of the cube texture at low annealing temperatures in highly rolled pure nickel. Acta Materialia, Vol. 55, No. 10, 2007, pp. 3531-3540.

[26] Lin, F. X., Y. B. Zhang, W. Pantleon, and D. Juul Jensen. Supercube grains leading to a strong cube texture and a broad grain size distribution after recrystallization. Philosophical Magazine, Vol. 95, No. 22, 2015, pp. 2427-2449.

[27] Zhang, Y. B., A. Godfrey, Q. Liu, W. Liu, and D. Juul Jensen. Analysis of the growth of individual grains during recrystallization in pure nickel. Acta Materialia, Vol. 57, No. 9, 2009, pp. 2631-2639. 